\title{
Value and Interpretation of Resection Margin after a Colonoscopic Polypectomy for Malignant Polyps
}

\author{
Eun Jung Jang, Dae Dong Kim, Chang Ho Cho ${ }^{1}$ \\ Colorectal Clinic, Department of Surgery, ${ }^{1}$ Department of Pathology, Daegu Catholic University Medical Center, Catholic University of Daegu \\ College of Medicine, Daegu, Korea
}

Purpose: This study was designed to compare the clinicopathologic findings of an endoscopic polypectomy for malignant polyps with subsequent surgery and to evaluate the appropriateness of the pathologic finding criterion of the resection margin as an indicator for surgery in cases of malignant colorectal polyps.

Methods: We examined the clinicopathologic characteristics, complications and prognoses among the patients who underwent a colonoscopic polypectomy in both our hospitals and at other hospitals from April 2003 and April 2010. These patients were divided into two groups, the group (non-operation group) that only underwent a polypectomy $(\mathrm{n}=37)$ and the group (operation group) that underwent a polypectomy with subsequent surgery $(\mathrm{n}=33)$.

Results: There were no differences between two groups in the ratios of the number of men to the number of women, the ages or the comorbidities. In terms of endoscopic findings, we found no differences between the two groups in the locations of the polyps, the sizes of the polyps, or the presence of stalks. However, ulceration of polyps was higher in the nonoperation group ( $51.5 \%$ vs. $21.6 \% ; \mathrm{P}=0.009)$, as was the case with submucosal invasion $(75.8 \%$ vs. $16.2 \% ; \mathrm{P}<0.005)$. When an endoscopic polypectomy was performed, incomplete resection margins and specimens with margins involved occurred more frequently in the operation group $(93.9 \%$ vs. $51.4 \%$; $\mathrm{P}<0.005)$, but no residual tumor was detected in 31 of $33(93.9 \%)$ patients in that group. One pathologist reviewed the specimens of 54 patients (operation group, 19; non-operation group, 36 ). Six of the 19 polyps (31.6\%) in the operation group and fifteen of the 36 polyps (41.7\%) in the non-operation group had a margin without cancer cells.

Conclusion: We may accept the criterion of a safe margin, including a coagulation zone. A multidisciplinary approach has to be developed by surgeons, endoscopists and pathologists based on a discussion of the risk factors for the patient before making a decision on the treatment treatment.

\section{Keywords: Malignant colorectal polyp; Endoscopic Resection criteria; Resection margin}

\section{INTRODUCTION}

In general, an adenomatous polyp in which cancer cells occur in intramucosal or submucosal lesions is called a malignant polyp [1]. Such malignant polyps have been reported to account for $2.6-9.7 \%$

Received: February 11, 2011 Accepted: July 15, 2011

Correspondence to: Dae Dong Kim, M.D.

Colorectal Clinic, Department of Surgery, University of Daegu Catholic

Medical Center, 3056-6 Daemyung 4-dong, Nam-gu, Daegu 705-718, Korea Tel: +82-53-650-4065, Fax: +82-53-624-7185

E-mail: silverpop@daum.net

(C) 2011 The Korean Society of Coloproctology

This is an open-access article distributed under the terms of the Creative Commons Attribution NonCommercial License (http://creativecommons.org/licenses/by-nc/3.0) which permits unrestricted noncommercial use, distribution, and reproduction in any medium, provided the original work is properly cited. of all polyps that are endoscopically removed (mean, 4.7\%) [2] and 9-11\% of all polyps that are surgically removed [3]. In past years when endoscopy and endoscopic treatment were at their initial stages, malignant polyps were mainly removed by surgical treatment. Therefore, the diagnosis and the infiltration of the malignant polyp were accurately identified. As endoscopic resections of malignant polyps have been conducted since 1970, the uncertainty in the diagnosis and in the treatment of malignant polyps has increased due to uncertain information on the endoscopically-resected tissues. Conventionally, in the case of adenomas restricted intramucosally with no lymphovascular metastasis, a successful treatment was expected when using an endoscopic was resection. On the contrary, in the case of submucosal invasion, the American Joint Committee on Cancer (AJCC) recommended surgical treatment in cases involving poor histological differentiation, un- 
clear resection margin, and lymphovascular metastasis [4]. However, after the surgery recommended by AJCC, clinical cases with no residual tumor were sometimes observed using histologic examination. This result raises the question of whether the appropriate treatment method had been applied. Accordingly, in order to investigate factors in tissues resected before surgery that affect surgical treatment, we conducted this study on patients who were suspected of having a malignant polyp on histologic examination after a colonoscopic polypectomy and who subsequently underwent surgical treatment, but who had no residual cancer in the final histologic examination after the surgery.

\section{METHODS}

This study was conducted on 70 patients who had undergone an endoscopic polypectomy for malignant polyps at the authors' hospital and at other hospitals from April 2003 to April 2010. After the polypectomy, the patients were divided into the surgery group and the non-surgery group, and their clinical and pathological characteristics, complications and prognoses were retrospectively investigated. Patients with malignant polyps in the rectum to which a full-thickness resection could be applied, such as transanal excision, with rectal cancer, with anal cancer treated with chemotherapy before surgery, and with genetic diseases, such as familial adenomatous polyposis, were excluded.

Endoscopic resection included a plain polypectomy, an endoscopic mucosal resection in which the submucosal layer is treated with $0.9 \%$ saline-epinephrineby using a 23 -gauge needle to elevate lesions and the mucosal layer is then en-bloc resected using a loop snare, and an endoscopic submucosal dissection using an electrocautery knife. A laparotomy or a laparoscopic colorectal resection was conducted as a surgical treatment. Pathological examinations were conducted on tissue samples endoscopically resected to investigate tumor size, resection margin status, histological type and differentiation, invasion depth, and lymphovascular invasion. For endoscopic dissection of the submucosal layer, the resection margin was clearly identified. Meanwhile, depending on the tissue samples, for mucosal resection, some cases in which the resection margin had not been identified were included. The invasion depth was divided into the mucosal and the submucosal layers. A free margin of $2 \mathrm{~mm}$ or more in the resection margin was included in the criterion for a complete resection, but the area coagulated by electrocautery was not included.

The resection margin status was defined as a complete resection when the free margin $\geq 2 \mathrm{~mm}$, as an incomplete resection when $1 \mathrm{~mm} \leq$ free margin $<2 \mathrm{~mm}$, as positive when cancer was present in the resection margin or when the free margin was less than $1 \mathrm{~mm}$, and as uncertain when the accuracy of the resection margin was uncertain due to piecemeal resection. In addition, the surgery criteria of the authors' hospital included residual cancer in the resection margin, incomplete securing of the resection margin, poor histologic differentiation, and lymphovascular metastasis in the tissue samples.

The pathologic reexaminations of the tissue samples were conducted by one pathologist. In particular, samples from the initial endoscopic polypectomies, which had been obtained from patients who had been reported to have no residual cancer after surgery, were carefully reexamined. At that time, the distance to the resection margin, including the coagulated area, was measured again.

For observation of the outcome observation, abdominal computed tomography (CT) was conducted to identify lymphatic metastasis before and after the endoscopic polypectomy, or before and after surgery. An endoscopic examinations were conducted on patients who had undergone endoscopic polypectomies without surgical treatment to follow-up on the lesion and were performed 2 weeks after the treatment, which was the earliest examination; this was generally followed by colonoscopy at 2-8 weeks, 4-6 months, and 2-3 years after the treatment. The mean follow-up period was 24 months.

A statistical analysis was conducted using SPSS ver. 14.0 (SPSS Inc., Chicago, IL, USA). Chi-square and Independent t-tests were performed, depending on the characteristics of the variables, to test statistical significance. P-values $<0.05$ were considered statistically significant.

\section{RESULTS}

For a comparative analysis, a total of 70 patients was divided into two groups: 37 patients (non-surgery group) who had undergone an endoscopic polypectomy and 33 patients (surgery group) who had undergone surgical treatment after a polypectomy. No significant differences in general characteristics, such as gender, age, and concurrent diseases, were found between the two groups (Table 1).

In the comparison of gross findings on the characteristics of the polyp, no differences in polyp location, size and stalk were found, but more surface ulceration was shown in the surgery group $(21.6 \%$

Table 1. Characteristics of the patients

\begin{tabular}{lccc}
\hline & $\begin{array}{c}\text { Non-operation } \\
\text { group }(\mathrm{n}=37)\end{array}$ & $\begin{array}{c}\text { Operation group } \\
(\mathrm{n}=33)\end{array}$ & P-value \\
\hline $\begin{array}{l}\text { Gender } \\
\text { Male }\end{array}$ & $25(67.6)$ & $23(69.7)$ & NS \\
$\quad$ Female & $12(32.4)$ & $10(30.3)$ & \\
Age (yr) & & & NS \\
$<60$ & $12(32.4)$ & $15(45.5)$ & \\
$\geq 60$ & $25(67.6)$ & $18(54.5)$ & \\
Comorbidity & & & NS \\
No & $30(81.1)$ & $23(69.7)$ & \\
Yes & $7(18.9)$ & $10(30.3)$ & \\
\hline
\end{tabular}

Values are presented as number (\%).

Comorbidity is disease of two or more organs, such as the heart, lung, kidney or endocrine organ. 
vs. $51.5 \%$; $=0.009)$. In the comparison of pathologic findings, well or moderate differentiation was shown in both groups, and submucosal invasion was shown more in the surgery group than in the non-surgery group $(16.2 \%$ vs. $75.8 \%$; $\mathrm{P}<0.005)$ (Table2). For resection margin status, an incomplete resection was shown more in the surgery group than in the non-surgery group according to the histologic findings at the time of treatment $(37.8 \%$ vs. $84.8 \%$ ). Based on the aforementioned, the results for the resection margin, which significantly affected surgical treatment, were analyzed in detail.

Table 2. Clinicopathologic characteristics of polyps

\begin{tabular}{|c|c|c|c|}
\hline & $\begin{array}{l}\text { Non-operation } \\
\text { group }(\mathrm{n}=37)\end{array}$ & $\begin{array}{l}\text { Operation group } \\
\quad B(n=33)\end{array}$ & P-value \\
\hline Location & & & NS \\
\hline Right colon & $8(21.6)$ & $4(12.1)$ & \\
\hline Left colon & $19(51.4)$ & $17(51.5)$ & \\
\hline Rectum & $10(45.5)$ & $12(36.4)$ & \\
\hline Size (mm) & & & NS \\
\hline $0-9$ & $9(24.3)$ & $4(12.1)$ & \\
\hline $10-19$ & $23(62.2)$ & $23(69.7)$ & \\
\hline $20-29$ & $4(10.8)$ & $5(15.2)$ & \\
\hline $30-39$ & $1(2.7)$ & $1(3.0)$ & \\
\hline Stalk & & & NS \\
\hline No & $25(67.6)$ & $21(63.6)$ & \\
\hline Yes & $12(32.4)$ & $12(36.4)$ & \\
\hline Ulcer & & & 0.009 \\
\hline No & $29(78.4)$ & $16(48.5)$ & \\
\hline Yes & $8(21.6)$ & $17(51.5)$ & \\
\hline Differentiation & & & NS \\
\hline Well & $20(54.1)$ & $6(18.2)$ & \\
\hline Moderate & $17(45.9)$ & $27(81.8)$ & \\
\hline Poor or signet ring cell & $0(0.0)$ & $0(0.0)$ & \\
\hline Margin & & & 0.001 \\
\hline Complete $^{\mathrm{a}}$ & $15(40.5)$ & $2(6.1)$ & \\
\hline Incomplete $^{b}$ & $7(21.6)$ & $3(9.1)$ & \\
\hline Positive $^{c}$ & $6(8.1)$ & $9(27.3)$ & \\
\hline Undetermined & $9(29.7)$ & $19(57.6)$ & \\
\hline Depth of Invasion & & & $<0.005$ \\
\hline Mucosa & $31(83.8)$ & $8(24.2)$ & \\
\hline Submucosa & $6(16.2)$ & $25(75.8)$ & \\
\hline CT nodal state & & & NS \\
\hline Absent & 37 (100) & $32(97)$ & \\
\hline Present & $0(0)$ & $1(3)$ & \\
\hline
\end{tabular}

Values are presented as number (\%).

${ }^{\mathrm{a}} \geq 2 \mathrm{~mm} .{ }^{\mathrm{b}} 1 \mathrm{~mm} \leq$ but $<2 \mathrm{~mm} .{ }^{\mathrm{c}}<1 \mathrm{~mm}$.
Among the patients who had not undergone surgical treatment, the resection margin was shown to be positive in 6 patients of 22 patients with incomplete securing of the resection margin or with a positive or an uncertain resection margin. Histologic reexamination after endoscopic follow-up was conducted to determine the conduct of surgical treatment in these six patients due to a brain lesion in one patient, an intramucosal lesion in three patients, a personal reason in one patient, and old age in one patient. However, no additional surgical treatment was conducted on these six patients as no cancer was found on the histologic reexamination. In cases of incomplete resection and uncertain resection margin, no surgical treatment was conducted as an intramucosal lesion was shown in most cases. An incomplete resection was shown in one patient with submucosal invasion, and surgical treatment was recommended. Endoscopic histologic examination was conducted under the patient's permission as good differentiation of the lesion and no lymphovascular metastasis were shown. As no residual cancer was found, no surgical treatment was conducted. Endoscopic histologic examinations were conducted on the remaining patients as intramucosal lesions were shown in all of them. The result of the examination also showed no residual cancer.

Among the surgery group, an endoscopic complete resection was performed in two patients, one who showed an intramucosal lesion and one who showed a submucosal lesion. However, these two patients still desired surgical treatment. Among the remaining 31 patients, surgical treatment was conducted on 15 patients due to an uncertain resection margin, 7 patients due to an incomplete resection, and 9 patients due to a positive resection margin. Lymphatic metastasis on abdominal CT was suspected in one patient who showed submucosal invasion and a positive resection margin. Among the 33 patient who had undergone surgical treatment, no residual cancer was observed in 31 patients $(93.9 \%)$ as a result of the final histologic examination. An incomplete resection

Table 3. Characteristics of resection margin on the review slide

\begin{tabular}{ccc}
\hline & $\begin{array}{c}\text { Non-operation group } \\
(\mathrm{n}=36)\end{array}$ & $\begin{array}{c}\text { Operation group } \\
(\mathrm{n}=19)\end{array}$ \\
\hline Complete & 15 & 6 \\
Mucosa & 13 & 2 \\
Submucosa & 2 & 4 \\
Incomplete & 8 & 6 \\
Mucosa & 7 & 1 \\
Submucosa & 1 & 5 \\
Undetermined & 10 & 7 \\
Mucosa & 10 & 5 \\
Submucosa & - & 2 \\
Positive & 3 & - \\
Mucosa & - & \\
Submucosa & 3 & \\
\hline
\end{tabular}




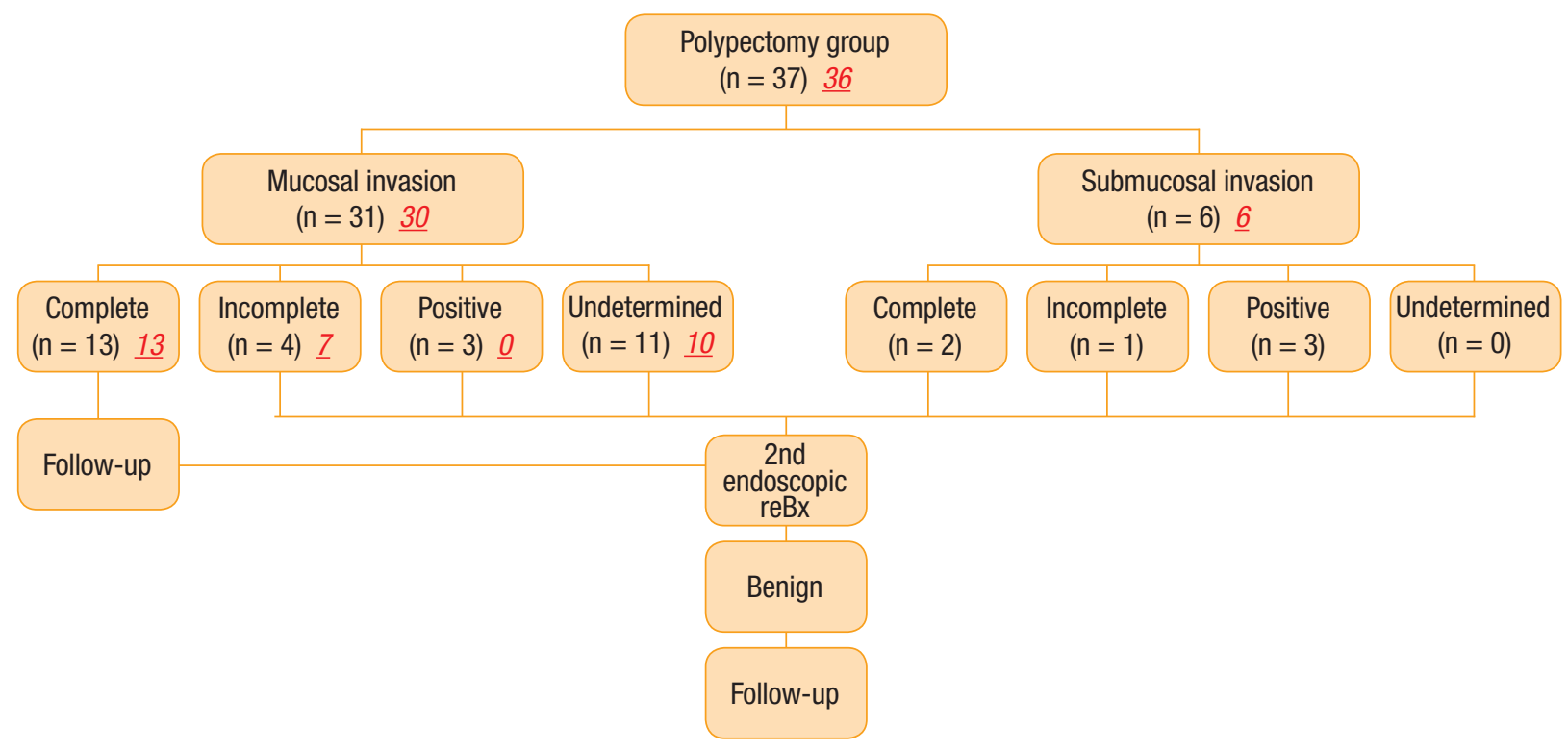

Fig. 1. Result of margin in polypectomy group. Red color letter means result of review margin.

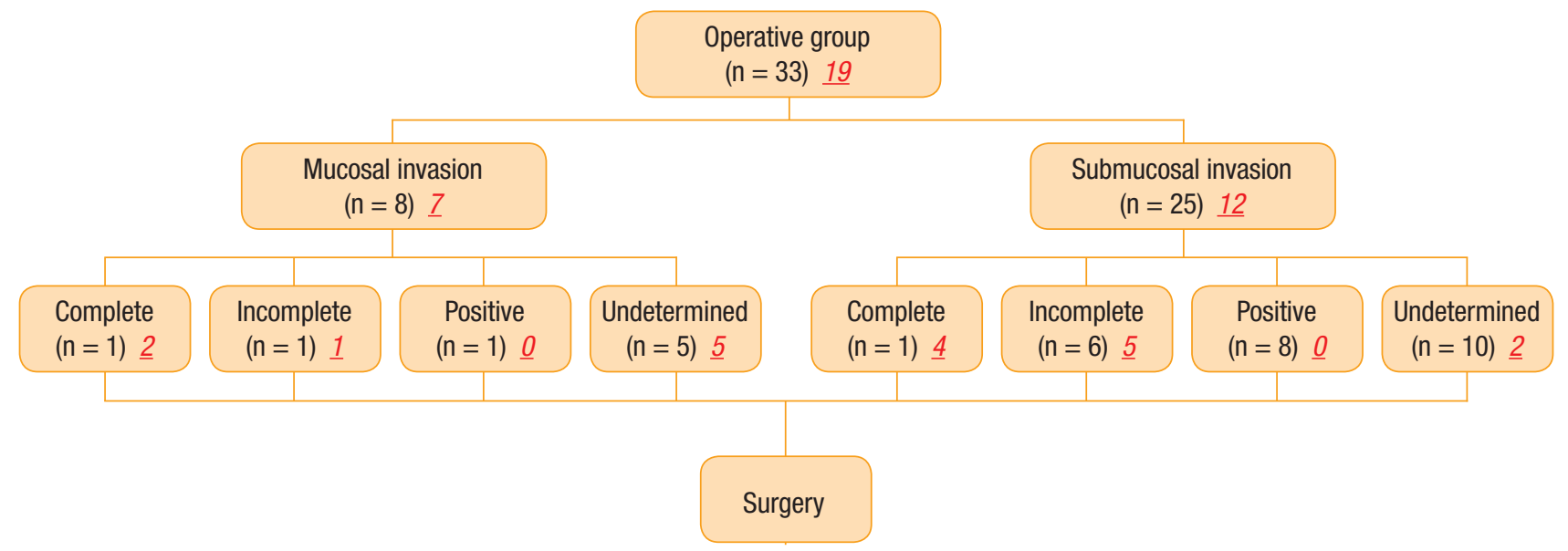

Fig. 2. Result of margin in operation group. Red color letter menas result of review margin.

and an uncertain resection margin, respectively, was observed in two patients who showed residual cancer. The pathologic findings of the initial polypectomies in the surgery group were reexamined by one pathologist, and at that time, the distance between the tumor and the resection margin, including the coagulated area, was measured. The numbers of samples tested before surgery were shown to be 19 in the surgery group and 36 in the non-surgery group. According to the results of the sample testing, complete resections were shown in 6 of 19 patients (31.6\%) in the surgery group and in 15 of 36 patients (41.7\%) in the non-surgery group. An incomplete resection with $1 \mathrm{~mm} \leq$ resection margin $<2 \mathrm{~mm}$ was shown in 6 of 19 patients (31.6\%) in the surgery group and in 8 of 36 patients (22.2\%) in the non-surgery group (Table 3, Figs. 1-2). Among the 13 patients who had shown a complete resection of an intramu- cosal lesion in the non-surgery group, an incomplete resection and an uncertain resection margin were shown in one patient. Among the four patients who had shown an incomplete resection, a complete resection was shown in one patient. Both patients who had shown a positive resection margin in the non-surgery group showed an incomplete resection. Among the 11 patients who had shown an uncertain resection margin, a complete resection was shown in one patient.

The results of histologic reexaminations of the samples from the patients who had shown submucosal lesions in the non-surgery group before and after reexamination were consistent. Furthermore, as a result of the histologic reexaminations of the intramucosal lesions in the surgery group, a complete resection was shown in one patient who had shown a positive resection margin. As a 
Journal of The Korean Society of Value and Interpretation of Resection Margin after a Colonoscopic Polypectomy for Malignant Polyps Coloproctology

3-1
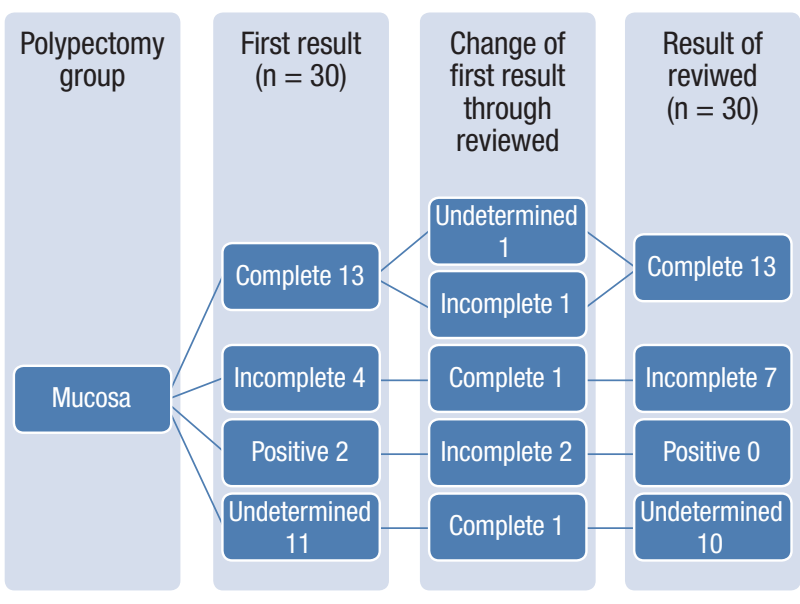

3-3

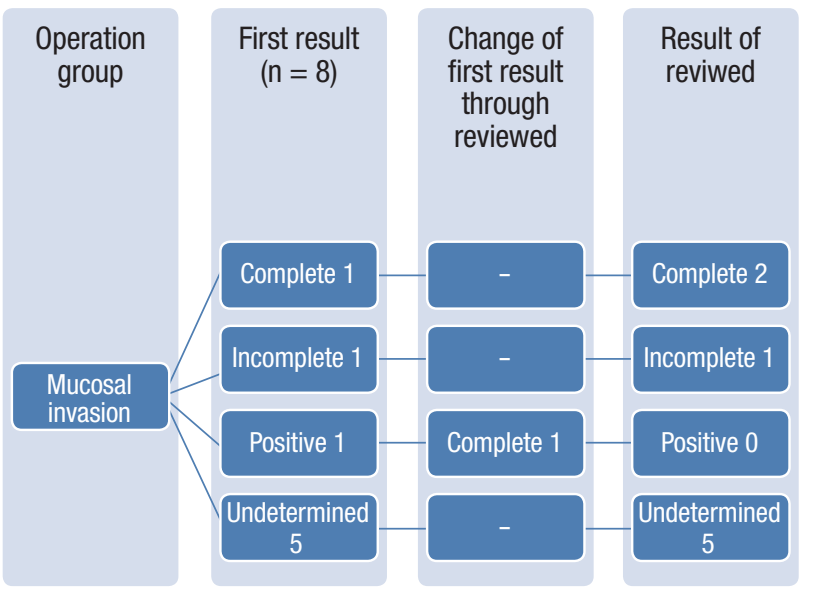

Fig. 3. Compared figure with excepted vs. included coagulation zone.

result of histologic reexaminations of the submucosal lesions in the surgery group, one of two patients who had shown an incomplete resection showed a complete resection, all four patients who had shown a positive resection margin showed an incomplete resection, and three of five patients who had shown an uncertain resection showed a complete resection. The aforementioned results were inconsistent with those of the preliminary examination (Fig. 3).

Identifying the exact presence of lymphovascular invasion in the tissue samples from patients who had undergone a polypectomy due to cutting problems in the preparation of tissue samples in the cases of the partial removal of the tissue or removal by piecemeal resection was difficult. Accordingly, the results of analyzing lymphovascular invasion were excluded from this study as no statistical significance was found due to the small number of the patients who showed significant results.

During the follow-up, one patient in the surgery group underwent anticancer therapy due to recurrence caused by lung metas-
$3-2$

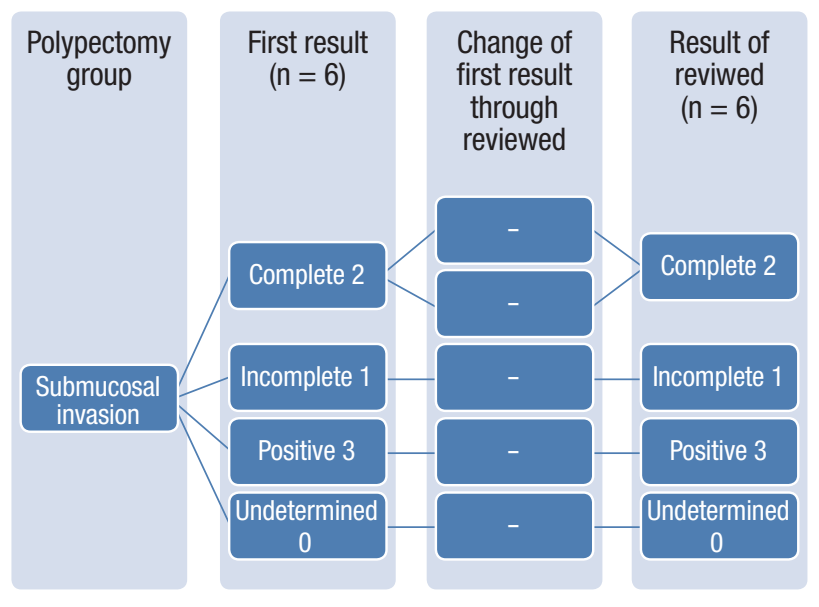

3-4

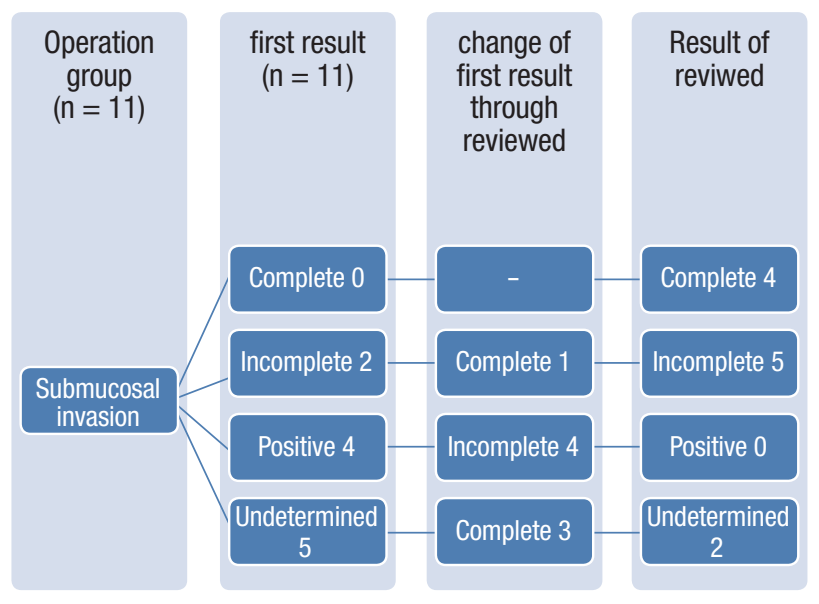

tasis. A complete resection was shown in this patient, who had shown a submucosal lesion on the histologic examination before surgery and no lymphatic metastasis. Meanwhile, no recurrence was found in the non-surgery group. No cancer-related death was found in either group. One patient in the surgery group died of pneumonia, independently of the surgery, during the follow-up period. No recurrence was found in the remaining 34 patients, but three patients in the non-surgery group were lost during the follow-up period. The mean follow-up period was 245 months (range, 0.9 to 69.1 months)

\section{DISCUSSION}

Most colorectal cancer has been reported to start as an adenoma and to occur via the adenoma-carcinoma sequence. Accordingly, studies on endoscopic resections of adenomas have been actively conducted [5]. Morson et al. [6] and Hermanek et al. [7] classified high-risk and low-risk groups of malignant polyps according to 
polyp size, histologic finding, stalk invasion, depth of tumor invasion, growth of sessile polyp, and vascular and lymphatic invasion. They reported that malignant polyps could be effectively treated by using a complete local resection in the patients who had welldifferentiated or moderately differentiated adenocarcinomas with no vascular and lymphatic invasion and who under regular endoscopic follow-ups. However, the aforementioned criteria could only be applied in cases of complete resection into a single piece. For piecemeal resection, surgical treatment should be considered due to low pathohistological accuracy [8].

More unfavorable histologic findings have been reported in sessile polyps. Nevertheless, many studies reported that an endoscopic polypectomy alone was sufficient to treat sessile polyps, regardless of polyp type, in low-risk groups that showed no malignant resection margin, good differentiation and no lymphovascular invasion [9]. As shown in this study, in the endoscopic examination, no difference in the prevalences of pedunculated polyps and sessile polyps was found between the two groups. However, in the case of ulceration on the polyp surface, surgical treatment was more preferred, which indicated a closer relationship with the degree of malignancy $[10,11]$.

For polyp removal, pedunculated polyps can be easily removed using a loop snare whereas sessile polyps or flat lesions are more likely to be removed via a piecemeal resection. In this case, despite the high possibility of a residual tumor or flat lesion cells in the resection margin, approximately $1 / 3$ of malignant polyps are treated via piecemeal resection $[11,12]$. Considering that en-bloc resection can be available in the case of endoscopic dissection of the submucosal layer and that an $84.9 \%$ form preservation and a $75.3 \%$ vertical and external free margin can be obtained [13], submucosal dissection should be considered as an appropriate method of removal for malignant polyps. That study [13] also showed that the number of patients who could be treated via endoscopic resection alone had increased since 2007 as a sufficient resection margin was secured due to increased numbers of endoscopic mucosal resections and endoscopic submucosal dissections.

The pathohistologic findings on the free resection margin showed that recurrence was $0-2 \%$ when the free margin $\geq 1 \mathrm{~mm}$ and 21 $33 \%$ when either the free margin $<1 \mathrm{~mm}$ or a residual tumor was present in the resection margin [14]. In general, recurrence has been believed to be unlikely for a safe resection margin of $\geq 2 \mathrm{~mm}$. However, considering tissues destroyed by diathermy, the criteria of resection margin size and no residual tumor in the resection margin remain to be investigated [10]. In this study, the resection margins, including the coagulated areas after polypectomy, were reexamined by one pathologist. Compared to the initial findings, the result of reexamination showed an increased number of complete resections and a decreased number of resection margin invasions. This result is likely associated with the inclusion of the coagulated area (Figs. 1, 2). Based on this result, measurement of the safe free margin, including the coagulated area, should be considered.
Muller et al. reported that intrasubmucosal vascular or lymphatic metastasis was observed in $17.6 \%$ of patients after a polypectomy, of whom $83.3 \%$ showed local lymph node metastasis or local recurrence [15]. However, most studies reported that vascular invasion was not recognized as an independent high-risk factors [9, 15], and many researchers, except for Cooper et al. [14], suggested that lymphatic invasion could be considered as a high-risk factor [9]. In fact, determining actual lymphatic invasion is difficult due to the retraction artifact of the resection margin caused by the resection itself $[14,16]$.

Although the reexaminations were performed by one pathologist in this study, conclusive results were not obtained due to the small number of samples clearly showing lymphovascular invasion. Nivatvongs et al. conducted a study targeting 151 patients who had had malignant polyps removed via surgical treatment. They reported that the subjects who had both lymphovascular metastasis and lymph node metastasis accounted for $31 \%$ of the patients [17] and that no patient with intramyomucosal pedunculated polyps showed lymphovascular metastasis, but the importance of lymphovascular metastasis significantly increased in cases of submucosal invasion. The aforementioned results are consistent with those of some other studies reporting a positive relationship between sessile polyps and the risk of lymph node metastasis [1820]. However, in this study, no recurrence was found in the case of sessile polyps that had shown favorable histologic results during the mean follow-up period.

Malignant polyps are divided into three grades, well, moderate and poor differentiation, according to tissue differentiation. Polyps with poor differentiation are not easily observed. Hassan et al. [18] reported that polyps with poor differentiation were observed in $7.2 \%$ of malignant polyps. No polyps with poor differentiation were found in this study. Despite this result, the reason that differentiation plays an important role in the determination of the treatment method of malignant polyps is the fact that more harmful results are believed to occur in tissues with poor differentiation $[2,6,14$, 21]. Coverlizza et al. [2] reported that poor differentiation was a very important risk factor as $50 \%$ of lesions with poor differentiation showed lymph node metastasis and that signet ring cell type was considered to be the same as poor differentiation.

If a malignant polyp is identified, either follow-up after endoscopic polypectomy or surgical treatment should be determined by considering the aforementioned risk factors. Colacchio et al. [22] conducted a study on 39 patients diagnosed with malignant polyps. They reported that a polypectomy alone was conducted on 15 patients who had refused surgical treatment and that lymphatic metastasis was found in $25 \%$ of the 24 patients who had undergone surgical treatment. They reported that prediction before surgery was impossible, that all patients diagnosed with malignant polyps should be considered high-risk, and that surgical treatment should be conducted on them. However, they acknowledged the selection bias of their study and suggested that the treatment method for malignant polyps could change [23]. On the other hand, Chapman 
et al. [24] reported that polyps completely resected by experienced endoscopists could be treated via endoscopic resection regardless of risk factors. The result of a study, which was recently conducted by Seit et al. [21] on 114 patients who had undergone an endoscopic polypectomy of a malignant polyp, showed that poor outcomes were obtained from 60 high-risk patients due to the relevant malignant tumor whereas good outcomes were obtained from 54 low-risk patients regardless of the tumor. They suggested that a more active treatment should be conducted if risk factors are identified during the pathohistologic examination $[21,25]$. In this study, surgery was performed on the patients that were considered to have risk factors on the histologic examination after the polypectomy. However, on the final histologic examination, no residual cancer was found in 31 (93.9\%) of the 33 patients. Furthermore, good treatment outcomes without recurrence during the follow-up period were obtained from patients who had been considered to have risk factors after the polypectomy, but who had undergone follow-up according to their wishes or the endoscopist's judgment. Considering the aforementioned results, each patient's characteristics, histologic findings, risk of residual cancer, and risk of surgical treatment should be considered together in the selection of a treatment method appropriate for that patient.

For mucosal cancer, the treatment outcome can be followed-up via secondary endoscopic resection even though a complete resection is not obtained. Meanwhile, for submucosal cancer, the treatment method should be determined by considering various risk factors in the case of incomplete resection. In addition, for securing the resection margin, a result including the coagulated area is likely to be effective. In summary, if an appropriate treatment method for a malignant polyp is to be selected, a multidisciplinary approach to the risk factors of each patient among surgeons, endoscopists, and pathologists is recommended.

\section{CONFLICT OF INTEREST}

No potential conflict of interest relevant to this article was reported.

\section{REFERENCES}

1. Bond JH. Polyp guideline: diagnosis, treatment, and surveillance for patients with nonfamilial colorectal polyps. The Practice Parameters Committee of the American College of Gastroenterology. Ann Intern Med 1993;119:836-43.

2. Coverlizza S, Risio M, Ferrari A, Fenoglio-Preiser CM, Rossini FP. Colorectal adenomas containing invasive carcinoma. Pathologic assessment of lymph node metastatic potential. Cancer 1989;64: 1937-47.

3. Hackelsberger A, Frühmorgen P, Weiler H, Heller T, Seeliger H, Junghanns K. Endoscopic polypectomy and management of colorectal adenomas with invasive carcinoma. Endoscopy 1995;27:153-8.

4. Wayne JD, O'Brien MJ. Cancer in polyps. In: Cohen AM, Winawer SJ, editors. Cancer of the colon, rectum, and anus. New York: Mc-
Graw-Hil; 1995. p. 465-76.

5. Morson B. President's address. The polyp-cancer sequence in the large bowel. Proc R Soc Med 1974;67(6 Pt 1):451-7.

6. Morson BC, Whiteway JE, Jones EA, Macrae FA, Williams CB. Histopathology and prognosis of malignant colorectal polyps treated by endoscopic polypectomy. Gut 1984;25:437-44.

7. Hermanek P, Gall FP. Early (microinvasive) colorectal carcinoma. Pathology, diagnosis, surgical treatment. Int J Colorectal Dis 1986; 1:79-84.

8. Pizarro-Moreno A, Cordero-Fernandez C, Garzon-Benavides M, Cayuela A, Bozada-Garcia JM, Sobrino-Rodriguez S, et al. Malignant colonic adenomas. Therapeutic criteria. Long-term results of therapy in a series of 42 patients in our healthcare area. Rev Esp Enferm Dig 2009;101:830-6.

9. Netzer P, Forster C, Biral R, Ruchti C, Neuweiler J, Stauffer E, et al. Risk factor assessment of endoscopically removed malignant colorectal polyps. Gut 1998;43:669-74.

10. Soetikno RM, Kaltenbach T, Rouse RV, Park W, Maheshwari A, Sato T, et al. Prevalence of nonpolypoid (flat and depressed) colorectal neoplasms in asymptomatic and symptomatic adults. JAMA 2008;299:1027-35.

11. Bujanda L, Cosme A, Gil I, Arenas-Mirave JI. Malignant colorectal polyps. World J Gastroenterol 2010;16:3103-11.

12. Dell'Abate P, Iosca A, Galimberti A, Piccolo P, Soliani P, Foggi E. Endoscopic treatment of colorectal benign-appearing lesions $3 \mathrm{~cm}$ or larger: techniques and outcome. Dis Colon Rectum 2001;44: 112-8.

13. Puli SR, Kakugawa Y, Saito Y, Antillon D, Gotoda T, Antillon MR. Successful complete cure en-bloc resection of large nonpedunculated colonic polyps by endoscopic submucosal dissection: a metaanalysis and systematic review. Ann Surg Oncol 2009;16:2147-51.

14. Cooper HS, Deppisch LM, Gourley WK, Kahn EI, Lev R, Manley $\mathrm{PN}$, et al. Endoscopically removed malignant colorectal polyps: clinicopathologic correlations. Gastroenterology 1995 ;108:1657-65.

15. Muller S, Chesner IM, Egan MJ, Rowlands DC, Collard MJ, Swarbrick ET, et al. Significance of venous and lymphatic invasion in malignant polyps of the colon and rectum. Gut 1989;30: 1385-91.

16. Volk EE, Goldblum JR, Petras RE, Carey WD, Fazio VW. Management and outcome of patients with invasive carcinoma arising in colorectal polyps. Gastroenterology 1995;109:1801-7.

17. Nivatvongs S, Rojanasakul A, Reiman HM, Dozois RR, Wolff BG, Pemberton JH, et al. The risk of lymph node metastasis in colorectal polyps with invasive adenocarcinoma. Dis Colon Rectum 1991; 34:323-8.

18. Hassan C, Zullo A, Risio M, Rossini FP, Morini S. Histologic risk factors and clinical outcome in colorectal malignant polyp: a pooleddata analysis. Dis Colon Rectum 2005;48:1588-96.

19. Cranley JP, Petras RE, Carey WD, Paradis K, Sivak MV. When is endoscopic polypectomy adequate therapy for colonic polyps containing invasive carcinoma? Gastroenterology 1986;91:419-27.

20. Wolff WI, Shinya H. Definitive treatment of "malignant" polyps 
of the colon. Ann Surg 1975;182:516-25.

21. Seitz U, Bohnacker S, Seewald S, Thonke F, Brand B, Bräiutigam T, et al. Is endoscopic polypectomy an adequate therapy for malignant colorectal adenomas? Presentation of 114 patients and review of the literature. Dis Colon Rectum 2004;47:1789-96.

22. Colacchio TA, Forde KA, Scantlebury VP. Endoscopic polypectomy: inadequate treatment for invasive colorectal carcinoma. Ann Surg 1981;194:704-7.

23. Wilcox GM, Anderson PB, Colacchio TA. Early invasive carcino- ma in colonic polyps. A review of the literature with emphasis on the assessment of the risk of metastasis. Cancer 1986;57:160-71.

24. Chapman MA, Schofield JH, Hardcastle JD. Management and outcome of patients with malignant colonic polyp identified from the Nottingham Colorectal Screening Study. Colorectal Dis 2000; 2:8-12.

25. Mitchell PJ, Haboubi NY. The malignant adenoma: when to operate and when to watch. Surg Endosc 2008;22:1563-9. 